\title{
Fishing industry and related perspectives on the issues raised by no-take marine protected area proposals
}

\section{Jones P.J.S.}

Department of Geography, University College London (UCL), Pearson Building, Gower Street, London WC1E 6BT

Tel 0207679 0528, Fax 02076790565

P.J.Jones@ucl.ac.uk

\begin{abstract}
In the face of growing calls for no-take MPAs (NTMPAs), the views of fishing industry representatives in SW England on related issues are analysed. Only $23 \%$ thought NTMPAs were the way forward and a range of concerns were expressed, $e g$ that the 'terrestrial' protected areas approach and related biodiversity conservation objectives will be extended to the seas, and that fish yield reductions from the loss of access to NTMPAs are very unlikely to be compensated for through spillover/export. Some interesting approaches to ameliorating these concerns emerged, such as being open and honest that NTMPAs are primarily intended to achieve biodiversity conservation benefits, reducing uncertainty concerning the potential for any secondary fisheries spillover/export benefits, justifying NTMPAs on an objective, rational basis, rather than on a subjective, precautionary basis, and the quid pro quo streamlining of wider fisheries management approaches. This research reveals a more diverse range of perspectives amongst fishing industry representatives on the issues raised by NTMPA proposals than is often assumed.
\end{abstract}

Key words: marine protected areas, fishing industry views

This is the author's version of the published paper, which is freely available for download. The published format is subject to copyright, but this version is exactly the same

\section{Citation}

Jones P.J.S. (2008) Fishing industry and related perspectives on the issues raised by no-take marine protected area proposals. Marine Policy 32(4), 749-758.

doi:10.1016/j.marpol.2007.12.009 


\section{Introduction}

No-take marine protected areas (NTMPAs) can be defined as marine areas in which the extraction of living and non-living resources is permanently prohibited, except as necessary for monitoring or research to evaluate effectiveness [1]. There is a growing focus on the potential of NTMPAs to address concerns about declines in marine biodiversity and associated declines in the 'health' of marine ecosystems and fish stocks [2]. Many scientists argue that NTMPAs are a key way forward as a continued reliance on conventional fisheries management approaches (CFMAs), such as quotas and technical measures, will not address such concerns, whilst many other scientists argue that the continued improvement of CFMAs is the key way forward and that NTMPAs would be a distraction from this [3]. Meanwhile, the IUCN have recommended that $20-30 \%$ of each marine habitat should be designated as NTMPA by 2012 [4]. It has recently been estimated that only $\sim 0.2 \%$ of the total marine area under national jurisdiction $(<200 \mathrm{~nm})$ is NTMPA whilst $\sim 1.5 \%$ is partially protected as 'multiple-use' MPA [5], so \% targets such as that set by the IUCN are both ambitious and controversial $[2,3,5,6]$. In the midst of NTMPA debates amongst fisheries scientists and marine ecologists, it is important to consider the perspectives amongst fishing industry representatives. Considerations of these perspectives are notably lacking in NTMPA debates, even though fishing is both the key cause of the concerns on which NTMPA calls are based and the main activity that such designations will exclude.

This paper aims to address this by analysing different perspectives, amongst fishing industry representatives in south-west England, on the issues raised by NTMPA proposals. The background behind calls for NTMPAs in the UK will be considered and the approach to gathering information on different perspectives on these calls described. The different perspectives will be analysed with a particular focus on whether NTMPAs are the way forward, their objectives, uncertainty concerning their benefits, issues related to them concerning the ecosystem approach and precautionary principle, the balance between their use and wider fisheries management approaches, and issues related to their enforcement. Some general conclusions will then be drawn from these analyses.

\section{Background}

At a UK level, MPAs are a relatively recent aspect of conservation policies. Prior to 1981 there were no statutory provisions for MPAs in the UK so there was a reliance on voluntary marine nature reserves. New legal provisions for statutory marine nature reserves in 1981 were weak and the government was less than enthusiastic in approving proposals for such designations; as a result only 3 statutory marine nature reserves were ever designated. The EC Habitats Directive (1992) and the UK Regulations (1994) to implement it were therefore enthusiastically welcomed by marine conservationists as they required the designation and protection of marine special areas of conservation to protect marine habitats \& species [7]. Over 80 such designations are being implemented around the UK but these are multiple-use MPAs where activities that are compatible with the fulfilment of conservation objectives are provided for. There are growing concerns that fishing activities that are damaging marine conservation features, particularly demersal trawling on biogenic reefs, are being allowed. Only one NTMPA is currently officially designated: Lundy (in the Bristol Channel), with an area of $3.2 \mathrm{~km}^{2}$, which is equivalent to $0.002 \%$ of the area of the UK's territorial waters (inside $12 \mathrm{~nm}$ ).

The forthcoming Marine Bill ${ }^{1}$ is regarded by UK marine conservationists as a very important opportunity to provide for the recovery and conservation of marine ecosystems. The proposals for the Bill include

\footnotetext{
${ }^{1}$ For further information on the Marine Bill see www.defra.gov.uk/environment/water/marine/uk/policy/marinebill/index.htm and Jones [2006].
} 
creating a strategic marine spatial planning system, strengthening fisheries and environmental management arrangements, and introducing new tools to conserve marine wildlife, particularly 'flexible, objective-based marine conservation zones'. Environmental campaign groups are arguing that the Marine Bill will be a failure if it does not provide for the designation of an ecologically coherent network of NTMPAs and Greenpeace, in particular, are campaigning for a network of NTMPAs in the North Sea, covering $40 \%$ of the total area $^{2}$.

Calls for NTMPAs are not confined to campaigners: they are also coming from the UK scientific community. The Royal Commission on Environmental Pollution 2004 report 'Turning the Tide' [8] concluded that "it is clear that the complexity of marine ecosystems is being reduced [by fishing impacts], and with the change from complex food webs to simple food webs, resilience in the marine ecosystem is also being lost" (para. 5.36). Accordingly, it recommended that the UK Government should designate $30 \%$ of the UK's fisheries zone (out to $200 \mathrm{~nm}$ ) as NTMPAs, forming an ecologically coherent network and providing for the recovery of marine ecosystems and fish stocks.

In response to this report, Ben Bradshaw, the then Minister for Fisheries \& Nature Conservation, commented that the RCEP report "highlights what is probably the second biggest environmental challenge the world faces after climate change". He argued, however, that it would be premature to implement the RCEP recommendations as "we need to give time for the radical measures that we have already taken to have an impact before moving to possibly more radical measures." ${ }^{3}$ The official government response to this report further argued that whilst multiple-use MPAs have a role, including partial/seasonal fishing closures, it is uncertain about the scientific basis of the RCEP recommendation for NTMPAs [9]. It is therefore highly debatable whether the government will heed the calls for NTMPAs in its forthcoming Marine Bill [10]. However, NTMPAs remain on the agenda and are likely to feature prominently in Marine Bill debates, despite the government's reservations.

As well as the calls for NTMPAs by campaigners and scientists, the government's own former nature conservation agency has also called for NTMPAs. English Nature's Maritime Strategy $\left(2005^{4}\right)$ included the objective of fully protecting 20-30\% of each marine habitat type from all extractive and disturbing activities, as a key aspect of its proposals to restore marine ecosystems and conserve marine biodiversity. The new integrated agency, Natural England, has a marine campaign ${ }^{5}$ and their 'Strategic Direction' for 2006-2009 includes the aim 'to conserve, recover and enhance the marine environment' and the target to establish a coherent network of MPAs under the Marine Act by 2012. However, the extent to which these will be no-take is highly uncertain, Natural England's policy on MPAs ${ }^{7}$ only recognising NTMPAs as being essential for monitoring, benchmarking and research control objectives. Though the MPA policy recognises the need for marine ecosystem/biodiversity recovery and precaution in the face of uncertainty, it does not explicitly recognise the role of NTMPAs in fulfilling these needs.

There is also the Finding Sanctuary partnership project ${ }^{8}$ that aims to create a network of MPAs around South-West England, including 'high protection zones'. However, this initiative does not have any statutory powers or obligations related to it, though its partners include Natural England, who have and may be granted further MPA powers under the Marine Bill. At this stage, the aim is intended to be

\footnotetext{
${ }^{2}$ For further information on these campaigns see www.wcl.org.uk/marine_campaign.htm,

www.marinereservesnow.org.uk/ and www.greenpeace.org.uk/oceans

${ }^{3}$ From BBC interview on the launch of the RCEP report (news.bbc.co.uk/1/hi/sci/tech/4072503.stm)

${ }^{4}$ www.english-nature.org.uk/science/coasts_and_seas/default.asp

${ }_{6}^{5}$ www.naturalengland.org.uk/campaigns/marine/default.htm

${ }^{6}$ www.naturalengland.org.uk/pdf/about/Natural_England_Strategic_Direction.pdf

${ }^{7}$ www.naturalengland.org.uk/about/board/dec07/121207-NEBPU0807-MarineProtectedAreas.pdf

${ }^{8}$ www.finding-sanctuary.org
} 
fulfilled primarily through consensus-building amongst relevant stakeholders, including fishermen. There are also calls for NTMPAs from within the fishing industry itself, the Cornish and South Western Fish Producers Organisations having produced the No Take Zones video in 1999, in which it is argued that such designations offer some hope for the long term improvement of fish stocks.

Against this background, it is hardly surprising that fishermen and their representatives are aware that NTMPAs are 'on the agenda' and some are increasingly concerned that NTMPAs will be imposed on them, threatening their economic sustainability and 'way of life'.

\section{Methodology}

Whilst debates on NTMPAs are raging in policy and scientific circles, the views of the fishing industry are often neglected. This study is intended to provide an insight into the different perspectives amongst fishing industry representatives on the issues raised by NTMPA proposals in South-West England. It is intended that this will help provide for a better understanding of the factors behind fishing industry views in such debates and help promote their fuller participation. These issues were explored through a completely independent research project ${ }^{9}$ involving a programme of 51 semi-structured interviews over May-October 2005 with 57 fishing industry representatives (some interviews involved 2 or, on one occasion, 4 fishermen) in South-West England (West Dorset, Devon \& Cornwall). Interviews were conducted with 15 inshore fishermen (inside $6 \mathrm{~nm}$ therefore managed under domestic legislation by DEFRA and the Sea Fisheries Committees) and 16 offshore fishermen (outside 6nm therefore managed under the Common Fisheries Policy by the European Commission). Both static and towed, demersal and pelagic sector fishermen were interviewed. Interviews were also conducted with seven representatives of fisheries related organisations such as fishermen's associations, auctioneers/suppliers ('trawler agents'), five representatives of the co-operatives that manage quota under the CFP on behalf of fishermen ('producer organisations') and eight enforcement officers from the Sea Fisheries Committees and DEFRA. It is important to note that these categorisations are quite 'fuzzy' in that interviewees often had more than one affiliation, $e g$ producer organisation chairs who were active inshore/offshore fishermen, fishermen who were members of a Sea Fisheries Committee and had official positions in a fishermen's association, etc. For this reason, these categorisations are only employed in relation to the firstly reported question. For subsequent issues, these categorisations will not routinely be employed, in order to avoid misleading conclusions.

The interviews were taped and a report produced for each that was sent to the relevant interviewee(s) for confirmation that their views had been captured correctly. The quotes in the subsequent discussions are from these reports, rather than being completely verbatim quotes. The discussions during the interviews revolved around various themes and the interview findings were analysed on a qualitative basis using these themes. Apart from basic descriptive statistics, quantitative analyses were not employed as the interview findings represent qualitative information rather than 'data'. Percentages and numbers of interviewees (latter in brackets) are given in relation to the total number of interviewees that discussed a given issue, rather than necessarily as a percentage of the total number of interviewees. Due to rounding up/down errors, the percentages may not total to 100. The interview findings are reported in an anonymous manner. The results of this study are presented in full in the Research Report [11] that can be downloaded on line, but the key points are reported and discussed as follows.

\footnotetext{
${ }^{9}$ Costs related to the interviews were covered by a Sabbatical Research Grant from the Faculty of Social \& Historical Sciences, UCL. All the interviews were conducted and analysed by the author.
} 


\section{Results/discussion}

Are NTMPAs the way forward?

This key question was the last to be asked but it is reported first here as it forms an important basis for subsequent discussions. The distribution of views on this question is shown in Table 2. Overall, 23\% (13) of the interviewees considered NTMPAs to be the way forward, but only 16\% (6) of actual fishermen stated such support. There was a stark contrast between the views of the enforcers and the producer organisations in that whilst none of the interviewees from enforcement institutions thought NTMPAs were the way forward, $80 \%$ (4) of the interviewees from the producer organisations thought they were. A relatively large proportion (43\% (3)) of the fishing industry representatives also saw NTMPAs as the way forward. It could be argued that the producer organisation and industry representatives are taking a more politically strategic perspective, recognising that it is better to constructively engage in NTMPA debates than to be excluded from them, whilst the enforcers are taking a more pragmatic but reluctant perspective from the point-of-view of people who would have to enforce NTMPAs.

Table 1 Different views on the question 'Are NTMPAs the way forward?'

\begin{tabular}{|l|l|l|l|}
\cline { 2 - 4 } \multicolumn{1}{c|}{} & No & Yes & Total \\
\hline Inshore & $73 \%(11)$ & $27 \%(4)$ & 15 \\
\hline Offshore & $91 \%(20)$ & $9 \%(2)$ & 22 \\
\hline Representatives & $57 \%(4)$ & $43 \%(3)$ & 7 \\
\hline Producer Organisations & $20 \%(1)$ & $80 \%(4)$ & 5 \\
\hline Enforcers & $100 \%(8)$ & $0 \%(0)$ & 8 \\
\hline Overall & $\mathbf{7 7 \% ( 4 4 )}$ & $\mathbf{2 3 \% ( 1 3 )}$ & $\mathbf{5 7}$ \\
\hline
\end{tabular}

The discussions that led to this question and underlie the answers revolved, amongst others, around five inter-related themes, on which the subsequent reporting and discussions of results will be based:-

- the objectives of NTMPAs;

- uncertainty concerning potential NTMPA benefits;

- the ecosystem approach and precautionary principle;

- balance between the use of wider fisheries management approaches and NTMPAs;

- enforcement issues

\section{The objectives of NTMPAs}

Fishermen in the UK, as in most of the world, have enjoyed the rights to fish the total sea area, with the exception of safety, security, etc exclusion zones, provided stocks are present and it is technically and economically feasible to exploit them. Conservation measures are imposed, such as quotas on certain species, partial/seasonal closures, licensed access and various technical restrictions. However, all these measures are aimed at fisheries conservation objectives and other than these, the basic presumption has been that all areas can be fished, under the legal and customary principle of 'the freedom of the seas'. This presumption is now being undermined by increasing calls for NTMPAs, in which all fishing is banned, primarily in order to achieve marine biodiversity conservation objectives. These calls arguably reflect a shift from a purely resource conservation focused view of the sea to a more ecocentric and preservationist influenced view, representing an extension of societal and scientific concerns to our seas 
[3]. However, there is no doubt that these calls raise many issues from the fishing industry's perspective as they represent a fundamental challenge, through the introduction of marine biodiversity conservation objectives, to marine access and exploitation decision-making processes.

Some interviewees explicitly recognised this, one stating that 'the seas are for fishing and for fishermen to fish, so why have nature conservation objective?', whilst another argued, in a similar vein, that 'the sea is the fishermen's heritage, that's all we've got and you can't take it away'. Overall, 36\% (16) argued that neither biodiversity nor fisheries conservation objectives are a valid justification for NTMPAs, mainly because the former are not applicable to the seas, as 'nobody is there to appreciate it' and 'the seas are so dynamic I don't see that this nature conservation approach is valid', whilst the latter are unlikely to be delivered, whilst $36 \%$ (16) considered that both objectives are equally valid, though often with reservations. The latter perspective is interesting in that it is consistent with the argument that NTMPAs represent a 'win-win' solution, in that they can confer benefits for both marine biodiversity and fisheries conservation $[12,13]$. However, 20\% (9) of the interviewees argued that NTMPAs should be primarily focused on biodiversity conservation objectives and that NTMPA advocates should not try and mis-sell them on the basis of their potential fisheries benefits:-

'I think that having primary biodiversity objectives would be the most practical, clear and honest approach. Whilst they might have coincidental fisheries benefits, they should not be sold on this basis as the potential benefits are too uncertain, as fishermen know well, so whilst win-win is a nice ideal, I do not think it is appropriate in reality'

This perspective is consistent with the argument that it should not be necessary to 'sell' the resource management benefits of NTMPAs [2], though the argument above is on pragmatic rather than ethical grounds. It is also consistent with growing recognition of the risks of over-selling the potential fishery yield benefits of NTMPAs [14]. Only 7\% (3) considered that NTMPAs should be primarily focused on fisheries objectives as 'the argument that NTMPAs will provide a good breeding and nursery ground for fish is convincing... I am very resistant to the idea of nature conservation through NTMPAs as I don't want to see what they can do on land to close areas, because a few grasshoppers and a worm are found on it, extended to the sea.' This message is similar to that from the quotes of those who think neither objectives are valid, in that they convey that many fishing industry representatives feel a sense of proprietorship, if not ownership, over the seas they fish and are very resistant to the extension to the marine environment of the 'terrestrial' protected areas approach and related biodiversity conservation objectives, though many others can see the validity of such objectives.

\section{Uncertainty concerning potential NTMPA benefits}

One of the arguments put forward by NTMPA advocates is that the fishing industry will gain through the spillover of adults and the export of propagules as the age and density of fish within NTMPAs increases $[15,16]$. Some critics of NTMPAs, however, argue that fish yield reductions from the loss of access to NTMPAs are very unlikely to be compensated for through such spillover and export [17, 18], a view supported by the finding that such benefits did not, in any of the North Atlantic MPAs studied, compensate for loss of fishing area [19]. The majority (71\% (27)) of interviewees agreed with the latter perspective, mainly on the basis that fish stocks around south-west England are too diverse, mixed and migratory for such benefits to flow, that benefits for spawning grounds can be achieved through partial/seasonal closures and that effort displacement will more than cancel out any such benefits (see later discussion). $11 \%$ (4) considered that such benefits are likely enough to flow to warrant trialling NTMPAs, whilst $18 \%$ (7) were already convinced such benefits will flow. All such convinced interviewees also stated that they considered NTMPAs to be the way forward. This indicates that reducing 
Jones P.J.S. (2008) Fishing industry and related perspectives on the issues raised by no-take marine protected area proposals. Marine Policy 32(4), 749-758. doi:10.1016/j.marpol.2007.12.009

uncertainty concerning the potential for spillover/export benefits could be a key to overcoming resistance to NTMPAs if they are, as is discussed above, to be pursued on the basis of fisheries conservation objectives.

It has been argued that resistance to NTMPAs might be overcome by fishermen learning through the experiences of their counterparts in other countries, who have become supporters of such designations by witnessing, first-hand, their spillover/export benefits [20]. The majority (83\% (19)) of interviewees, however, rejected this argument on the grounds that the demographic, political, ecological, etc differences between the fisheries around SW England and those around other countries, $e g$ New Zealand, mean that such reported benefits are not transferable to SW England.

\section{The ecosystem approach and precautionary principle}

Discussions on this theme were focused on interviewees' views on the ecosystem approach and the precautionary principle, as these are key elements of the forthcoming Marine Bill [10] and are often used to support arguments for NTMPAs [13]. 38\% (9) were critical of the ecosystem approach on the grounds that 'the seas are too complex to understand so I don't see that we can take an ecosystem approach, as we cannot understand the consequences of our interventions', and that this approach, in combination with the precautionary principle, 'could just be the means by which they finish off the UK fishing industry.' $21 \%$ (5) were very cautious about the precautionary principle on the grounds that 'we must balance the need for precaution with the consequences of taking precautionary measures' and 'NTMPAs should be used with precaution and certainly not as a means of implementing the precautionary principle'. $17 \%$ (4) were in favour of the ecosystem approach on the grounds that 'we do generally need to be more strategic in the way we manage our impacts on marine ecosystems' whilst just $8 \%$ (2) supported the precautionary principle: 'give it the benefit of the doubt.'

$21 \%$ (5) argued that as fish mortality from fishermen is being managed, then seal mortality should also be managed through culls, as part of the ecosystem approach, because seals are 'pests' that take an increasing proportion of stocks and to not manage them would be discriminatory, recognising that both fishermen and seals are top predators in marine ecosystems. 13\% (3) argued against this view on the grounds that seals represent a very small effort compared to fishermen and 'nature has always looked after itself.' This is a long standing debate and recent research [21] is inconclusive on whether increasing seal numbers in the North Sea might limit the ability of fish stocks to recover. The calls for seal culls as part of the ecosystem approach are consistent with the arguments put forward in Norway and reported by Corkeron [22]. He argues that a key principle behind ecosystem based fisheries management is that sustaining ecosystem structure and function supersedes maximising fisheries yield, and that culls justified on the basis of the ecosystem approach would invert this principle, therefore "science will have been applied poorly to policy, the tangential will have become mainstream, and ecosystem based fishery management could fail before it has been implemented internationally." Many marine conservationists in the UK would agree with this argument. Yaffee's [23] analysis of the three faces of ecosystem management would see such calls as being consistent with a more resource-use focused conceptualisation of the ecosystem approach, rather than an inversion of it, and that less dogmatic debates related to such calls can pave the way for a more landscape focused conceptualisation of marine ecosystems.

Another conceptualisation of the ecosystem approach amongst some interviewees was revealed by their arguments that fishing stocks and grounds is necessary to avoid them 'stagnating' and becoming infested by 'vermin' like starfish and anemones. This is consistent with the view, discussed above, that fishermen are an integral part of the ecosystem. 50\% (12) argued that demersal trawling is necessary to avoid the stagnation of grounds: 'fishermen are like the farmers of the sea in that they turn the ground over, thin the 
stocks and help maintain productivity', whilst 38\% (9) considered that such arguments are a reflection of the increasing defensiveness of fishermen, an attempt to justify what they do, and that the constant efforts of demersal trawlers to edge into 'virgin' grounds undermine such arguments. 8\% (4) argued that it is good to thin stocks to boost their productivity and prevent them becoming diseased and senile, an argument that is in keeping with density-dependent factors that form the basis of population and fisheries ecology, but that it is not necessary to dredge grounds.

Again, this comes down to how the ecosystem approach is conceptualised, marine ecologists arguing that fishing leads to reductions in species, habitat and functional diversity through habitat homogenization [24, 25]. However, the interviews revealed that some fishermen see non-target species as 'vermin' and grounds where biodiversity has increased through a lack of fishing as 'stagnant', leading to reduced fisheries productivity. This view is supported by evaluations of the 'Plaice Box' partial closure in the south-eastern North Sea, which reveal that non-target species richness increased whilst plaice abundance decreased [26]. One of the interviewees specifically referred to this case as supporting his argument that NTMPAs actually deplete stocks through stagnation, though the fisheries scientists consider this case to be inconclusive.

There is widespread agreement that fishing modifies habitats but the key question is whether such modification is seen as a positive or negative impact: '[a fisheries scientist] has argued with me that areas impacted by scallop dredgers simply support different communities and are modified rather than damaged. We accept semi-natural, ie modified, terrestrial habitats such as meadows, so why not accept the value of modified marine habitats?' Many fishermen see the impacts of fishing as positive, as they prevent stagnation, whilst many ecologists see them as negative, as they lead to biodiversity losses through habitat homogenization, a view shared by some fishermen: '[beam trawling fishermen] often say they have cleaned such [rocky] grounds up, but I argue to them that they have actually turned them into ecological deserts.' By contrast, modifying terrestrial habitats through less intensive farming tends to lead to biodiversity gains through increases in habitat heterogeneity. Where farmers more intensively modify the land, leading to biodiversity losses, this is seen as positive from a food resource production perspective, but if fishermen are like the 'farmers of the sea' it could be argued that they, like farmers, must accept that some areas must be 'set aside' to address concerns from ecocentric and preservationist perspectives, as part of the ecosystem approach.

This argument aside, the calls of some interviewees for seal culls to control 'pests' and fishing to prevent 'stagnation' represent a particular construction amongst some of the interviewees of the ecosystem approach, though whether this construction is consistent with that emerging from the Marine Bill remains to be seen. Similarly, many interviewees are very cautious about the precautionary principle due to its potential to adversely affect the industry if it is interpreted too stringently in favour of environmental protection, but it remains to be seen how this principle will actually be interpreted in decisions taken through the policy framework emerging from the Marine Bill. It is, however, interesting to note that the UK Government is piloting an ecosystem approach to managing fisheries through a project around southwest England ${ }^{10}$, during which many of the issues addressed in this section are likely to emerge.

A related issue that was discussed by $25 \%$ (13) of the interviewees was the need for a rational, objective approach to justify NTMPAs, as opposed to justifying them for subjective reasons, such as promoting 'ecosystem health', and on a precautionary basis: 'we need analytical, science-based decisions, not precautionary ones'; 'we need to start with demonstrating that there is a need for improved management

\footnotetext{
${ }^{10}$ DEFRA Science and Research: Ecosystem Approach to Fisheries (MF1001) http://www2.defra.gov.uk/research/project_data/More.asp?I=MF1001\&M=KWS\&V=ecosystem+approach\&SUBM $\underline{\mathrm{IT} 1=\mathrm{Search} \& \mathrm{SCOPE}=0}$
} 
and that NTMPAs can address this need. English Nature seems to take decisions on the basis of principles rather than examination of the facts and risks.' One interviewee quoted Patrick Moore, one of the co-founders of Greenpeace who is now a critic of the environmental movement: 'the green lobby lobby, in campaigning for NTMPAs, has "abandoned science and logic in favour of emotion and sensationalism"'. The UK Government also favours an objective approach, as a government spokesman stated, at the launch of the Marine Bill White Paper, that marine conservation zones could be permanently closed to all activities where this can be objectively justified on a 'fit for purpose' basis, but it remains to be seen what the burden of proof will be for NTMPA proposers in this respect. The RCEP Report [8] recommended a reversal of the burden of proof, in that the fishing industry should have to prove that the impacts of a particular fishing practice in a particular area will not harm the long-term sustainability of marine ecosystems. The requirement to objectively justify NTMPA proposals clearly contradicts this recommendation.

Given that NTMPAs are often called for in keeping with the precautionary principle, including as an insurance against uncertainty [13], objectively justifying such proposals could be a major hurdle for marine conservationists, particularly given that our understanding of marine ecosystems is relatively poor and the related challenges of establishing cause-effect relationships [27]. One of the strengths of NTMPAs has been argued to be their simplicity, in that "no evidence of damage or danger to particular species or habitats is required; all marine life is protected on principle" [28]. Arguments for the need to objectively justify NTMPA proposals clearly challenge arguments for NTMPAs based on principles and precaution.

\section{Balance between use of wider fisheries management approaches and NTMPAs}

$48 \%$ (25) of the interviewees considered that improving wider fisheries management approaches (WFMAs) was the way forward, rather than designating NTMPAs, which only $25 \%$ considered to be the way forward. This perspective is consistent with the arguments put forward by many fisheries scientists, as reviewed by Jones [3]. Many ways to improve WFMAs were discussed by the interviewees, including better and more consistent enforcement throughout Europe, restricting the more damaging and intensive forms of fishing, reducing wider effort, reducing bycatch, banning discards and introducing 'real time' closures. It is worth noting that there are ongoing initiatives to achieve many of these improvements, including initiatives led by the UK fishing industry to reduce bycatch through gear modifications and introduce 'real time' closures.

NTMPA advocates, however, argue that such WFMAs have their limitations and that NTMPAs have the potential to fulfil objectives that WFMAs cannot deliver, therefore we need to both improve WFMAs and designate NTMPAs, as these approaches are complementary [29]. Interestingly, this argument is focused on the delivery of fisheries benefits, but Roberts et al. [29] also argue that WFMAs cannot fully deliver marine biodiversity conservation objectives, therefore NTMPAs are essential to achieve such objectives, as does Jones [3]. This relates to the previous discussion on resistance to the extension of such objectives to the marine environment, but it is clear that many interviewees think the improvement of WFMAs is the way forward, rather than designating NTMPAs, as do many fisheries scientists.

One specific fisheries management approach that was discussed by $67 \%$ (35) of the interviewees was the use of partial/seasonal closed areas to protect spawning/nursery grounds: 'boxes' in CFP parlance. Of these, 86\% (30) supported such closures as they achieve fisheries conservation objectives whilst allowing such areas to be harvested, with some also pointing out that certain biodiversity conservation objectives can be achieved by such designations [26]. Many discussed the Trevose Box off the north Cornwall coast, which is closed under the CFP to vessels over $10 \mathrm{~m}$ for three months a year (January-March). This was 
proposed and supported by the fishing industry to protect spawning grounds, particularly of cod. The closure was undermined by the derogation allowing Belgian beam trawlers access in March and whilst this was seen by many interviewees as a major flaw, illustrating the political weaknesses of the CFP, there is still widespread support for such partial/seasonal closures amongst fishermen and their representatives.

The South Devon Inshore Potting Agreement (IPA) off Start Point was another partial/seasonal closure scheme that was supported by $25 \%$ (13) of the interviewees, all of whom considered it a 'win-win' solution in that it delivered both fisheries and biodiversity conservation benefits. A small no-trawl area has been designated off Start Point for over 60 years but in 1978 a series of temporary and permanent gear restrictions was introduced by fishermen through a zonation scheme, primarily to resolve conflicts between mobile and static gears. This zonation scheme was originally enforced through a 'gentlemen's agreement' [30] and this was reasonably effective, though transgressions by a small number of freeriders led to this scheme being statutorily reinforced through SFC byelaws in 2002.

Subsequent evaluations revealed that the IPA had not only helped resolve gear conflicts, but had also helped conserve target finfish/shellfish stocks and protect benthic habitat complexity [31, 32, 33]. On the basis of the 'win-win' benefits of the Start Point IPA, many interviewees argued that NTMPAs were not necessary, as this initiative, that was initiated and supported by the fishing industry, fulfils both fisheries and biodiversity conservation objectives whilst allowing compatible fishing activities to continue. The evaluations, however, reveal that the biodiversity benefits were limited in their degree and extent, as areas were conferred only partial and/or temporary protection, in that the zonation scheme provides for periodic trawling and, at the most restrictive, zones where only static nets and pots can be deployed. Whilst the direct impacts of static gears on benthic habitats are much less than those of towed gears, such impacts can be significant and there are also trophic and structural cascade effects related to the harvesting of certain species that can indirectly but significantly affect the structure and diversity of benthic habitats, as well as associated pelagic populations $[28,34,35]$. Proponents of NTMPAs therefore argue that full biodiversity restoration can only be achieved by full and permanent protection [28].

It could therefore be argued that WFMAs, including partial and/or seasonal closures such as the Trevose Box and the IPA zonation scheme, pursued primarily to fulfil fisheries conservation objectives, cannot fulfil the marine biodiversity conservation objectives it is proposed NTMPAs can deliver. Again, this relates to previous discussions on the fishing industry's resistance to the extension of such objectives to the marine environment and the need for a rational, objective approach to justify NTMPAs.

$47 \%$ (24) of the interviewees discussed whether large areas of the sea remain unfished under WFMAs, thereby providing de facto NTMPAs, as argued by Kaiser [36]. This is a key issue as many proponents of NTMPAs argue that former natural refuges, where fishing was not possible or feasible, are increasingly fished due to technological developments, increased general effort and the depletion of populations elsewhere, and that NTMPAs are needed to substitute the function of former natural refuges in sustaining ecosystems and fish populations [15, 29]. 71\% (17) of the interviewees agreed with Kaiser that large areas remain unfished, including 6 inshore fishermen, but some qualified this as only being the case during bad weather. One interviewee also recognised that such areas were becoming fewer with new technologies whilst another recognised that "they could close barren areas with little impact, but not important, productive fishing grounds, but I can see that whilst this might have little pain it would probably provide little gain". $25 \%$ (6) of the interviewees argued that most, if not all, areas were fished at some time by some gear, five of whom were inshore fishermen whilst one was a general industry representative. One offshore fisherman who was formerly an inshore fisherman considered that there are such natural refuges offshore "but inshore, every inch of ground is fished".

It is clear that many fishing industry representatives consider that much of the sea is not fished and thereby fulfils a natural refuge role, as argued by Kaiser [36]. This argument is supported by the findings 
of Eastwood et al. [37] that the maximum spatial extent of demersal trawling in the Fishing Zone around England and Wales in 2004 was $21.4 \%$, ie nearly $80 \%$ of the seabed was apparently unfished that year, though this could be an underestimate for several reasons, $e g$ effort may shift on a year-to-year basis, excludes static demersal and all pelagic fishing. Their analysis was also based on VMS data which was only required for vessels over 14 metres in length, therefore the distribution of effort by smaller vessels, particularly inshore vessels, was not included, but it does support the argument agreed with by many interviewees that natural refuges from fishing continue to exist.

A closely related issue is whether effort displacement from NTMPAs will lead to former natural refuges becoming exploited, as again argued by Kaiser [36] and others [19, 38]. 37\% (19) of all the interviewees agreed in arguing that the displacement of fishing effort from NTMPAs would outweigh their spillover/export benefits, as well as increasing gear conflicts and disrupting the customary allocation of inshore grounds. Others have argued that such concerns are exaggerated, possibly motivated by fishermen's recognition that NTMPAs are more difficult to circumvent than WFMAs [39], as is discussed below, and that they do not warrant abandoning the concept of NTMPAs as they can be minimised through the careful design of NTMPAs [29]. It could also be argued that any restrictions on fishing are likely to lead to effort displacement therefore this concern is generic to fisheries management restrictions rather than being confined to NTMPAs [40]. The issue of effort displacement, however, is clearly a concern to many fishing industry representatives, as well as to some scientists.

Another issue that was discussed is whether there is any potential to streamline WFMAs, eg loosening restrictions on bycatch or days at sea, in return for accepting NTMPAs. 53\% (23) of the interviewees that discussed this thought that there was such potential, whilst $47 \%$ did not. Of the interviewees that thought there was such potential, $61 \%$ (14) did not otherwise consider NTMPAs to be the way forward. This indicates that there may be some potential for overcoming fishing industry objections to NTMPAs through the related streamlining of WFMAs. Whilst caution would have to be employed to ensure that the benefits of NTMPAs are not outweighed by the impacts of streamlining WFMAs, these findings indicate that industry objections to NTMPAs may be negotiable.

\section{Enforcement issues}

There are many factors that affect the potential enforceability of NTMPAs [2] but an important argument for such designations is that they are simpler and easier to enforce than WFMAs [41], in that it is not a matter of boarding a fishing vessel to check that it is licensed, within quota, adhering to minimum landing size \& technical restrictions, etc, but simply a matter of ascertaining and proving whether the vessel is fishing. NTMPAs also make it more difficult for fishers to be able to circumvent such complete restrictions [39]. It has, however, been counter-argued that such imposition is as unlikely to work as the attempted imposition of CFMAs has proved to be [42]. 50\% (19) of the interviewees that discussed such issues considered that NTMPAs are more easily enforced than WFMAs, for reasons such as the effectiveness of VMS, the fact that the burden of proof is limited to simply proving that a vessel was fishing within a given NTMPA, the eventual wider fisheries benefits that will flow from NTMPAs and the related potential for peer enforcement. On the other hand, an equal number of interviews $(50 \%(19))$ considered that NTMPAs were not more easily enforced than WFMAs, for reasons such as fishermen not being willing to comply with NTMPAs if they don't agree with or respect them, the economic/cultural imperative to catch fish and the limited proof provided by VMS. The potential of VMS is clearly a key issue in this respect and whilst VMS can be blocked or falsified, authorities are investigating the use of satellite imagery to overcome this, so VMS may become one of the most valuable tools for enforcing such designations [43]. However, at present VMS is only required under the CFP for vessels greater than $15 \mathrm{~m}$ 
Jones P.J.S. (2008) Fishing industry and related perspectives on the issues raised by no-take marine protected area proposals. Marine Policy 32(4), 749-758. doi:10.1016/j.marpol.2007.12.009

in length, so it would have to be required for smaller offshore and inshore vessels to be effective for all fleets.

One interviewee raised an interesting issue in arguing that 'NTMPAs are actually a retrograde step, as the presence of pots and potters is the best way of excluding trawlers. If you designate NTMPAs and take the potters out, the trawlers will get in to the NTMPA, as they can get round VMS, and the area will end up in a worse conservation condition than it was when it was a potting area.' Unless there is confidence that NTMPAs can actually be completely enforced, this argument raises the potentially worrying concern that NTMPAs that are illegally trawled could be less effective than static gear reserves, though this concern is countered by the growing confidence in the potential of VMS. Overall, it is clear that the fishing industry representatives were symmetrically divided on whether NTMPAs were more easily enforced than WFMAs.

\section{Conclusions}

In the face of growing calls for NTMPAs, the views of fishing industry representatives in SW England have been analysed through a programme of 51 interviews and these revealed some key concerns. Only $23 \%$ (13) of the interviewees thought NTMPAs were the way forward and it is clear that many fishing industry representatives feel a sense of proprietorship over the seas and are very resistant to the extension to the marine environment of the 'terrestrial' protected areas approach and related biodiversity conservation objectives. The majority of interviewees consider that fish yield reductions from the loss of access to NTMPAs are very unlikely to be compensated for through spillover/export as fish stocks around south-west England are too diverse, mixed and migratory for such benefits to flow, that benefits for spawning grounds can be achieved through partial/seasonal closure and that effort displacement will more than cancel out any such benefits. Many interviewees were critical of the ecosystem approach on the grounds that marine ecosystems are too large and complex to understand and manage, some also considering that culling seals should be recognised as an element of the ecosystem approach, as should fishing as a means of preventing 'stagnation'. Others were concerned that the ecosystem approach and the precautionary principle would be combined to justify draconian restrictions, such as NTMPAs.

Rather than designating NTMPAs, many interviewees considered the improvement of WFMAs to be the way forward, such as better and more consistent enforcement throughout Europe, restricting the more damaging and intensive forms of fishing, reducing wider effort, reducing bycatch, banning discards and introducing 'real time' closures. The use of partial/seasonal closures was one particular approach that was supported by the majority of interviewees, on the grounds that they provided for the fulfilment of both biodiversity and fisheries conservation benefits, contrary to the view of NTMPA advocates that certain marine biodiversity conservation and restoration objectives can only be delivered by full, permanent closures. Many interviewees considered that large areas of the sea remain unfished, thereby providing de facto protection, and that the displacement of effort from NTMPAs into such natural refuges would undermine both fisheries and biodiversity conservation objectives. The interviewees were symmetrically divided on whether NTMPAs were more easily enforced than NTMPAs, the potential of VMS being a key issue in this respect.

It must be stressed that many views were expressed in support of NTMPAs, the above conclusions being intended to highlight concerns related to NTMPA proposals amongst interviewees. Some interesting approaches to ameliorating these concerns also emerged from the interviews, such as being open and honest that NTMPAs are primarily intended to achieve biodiversity conservation benefits, reducing uncertainty concerning the potential for any secondary fisheries spillover/export benefits, and justifying NTMPAs on an objective, rational basis, rather than on a subjective basis 'in principle'. In particular, 
many fishermen who did not otherwise support such NTMPAs considered that objections to such designations might be overcome through the quid pro quo streamlining of WFMAs.

Some consider that the fishing industry should be excluded from NTMPA decisions in order to avoid their vested interests undermining marine biodiversity conservation objectives [44], whilst others argue that the top-down imposition of NTMPAs is as unlikely to work as the attempted imposition of WFMAs has proved to be [42]. The findings of these interviews indicate that whilst there may be some evidence in support of the former perspective, in that NTMPA proposals raise many fundamental concerns amongst some fishing industry representatives, there may be some potential for ameliorating such concerns. The debate on whether NTMPAs are the way forward will no doubt continue [3], particularly in relation to the forthcoming Marine Bill [10], as the divergences between the arguments of NTMPA advocates [8, 12, 16, $20,29,44]$ and sceptics $[9,19,37,38]$ in the UK reveal. Opponents of such designations from the fishing industry will continue to resist them, but the findings of this study reveal that the views of the fishing industry are not as uniform and unqualified as is often assumed. Whilst only a minority of interviewees considered NTMPAs as a way forward, discussions with them and the resistant majority revealed a diverse range of perspectives on the issues raised by NTMPA proposals. It is hoped that this research provides for a greater understanding and recognition of these perspectives in NTMPA debates and related initiatives.

\section{References}

[1] National Research Council. Marine protected areas: tools for sustaining ocean ecosystems. Washington, DC: National Academy Press, 2001.

[2] Jones PJS. Collective action problems posed by no-take zones. Marine Policy 2006; 30(2): 143156.

[3] Jones PJS. Point of view - Arguments for conventional fisheries management and against no-take marine protected areas: only half of the story? Reviews in Fish Biology and Fisheries 2007; 17(1): 31-43.

[4] Recommendations of the Vth IUCN World Parks Congress, Durban, South Africa. www.iucn.org/themes/wcpa/wpc2003/pdfs/outputs/recommendations/approved/english/pdf/r22.pdf

[5] Wood LJ, Fish L, Laughren J and Pauly D. Assessing progress towards global marine protection targets: shortfalls in information and action. Working Paper 2007-03, Fisheries Centre, University of British Columbia, 2007.

[6] Agardy T, Bridgewater P, Crosby MP, Day J, Dayton PK, Kenchington R, Laffoley D, McConney P, Murray PA, Parks JE and Peau L. Dangerous targets? Unresolved issues and ideological clashes around marine protected areas. Aquatic Conservation 2003;13(4):353-367.

[7] Jones PJS. Marine nature reserves in Britain: past lessons, current status and future issues. Marine Policy 1999; 23(4-5): 375-396.

[8] Royal Commission on Environmental Pollution. Twenty-Fifth Report: Turning the Tide Addressing the impact of fisheries on the marine environment. London: RCEP, 2005. www.rcep.org.uk/fishreport.htm

[9] Department for Environment, Food and Rural Affairs. The UK Government Response to the Royal Commission on Environmental Pollution's Twenty-Fifth Report Turning the Tide - Addressing the impact of fisheries on the marine environment. London: DEFRA, 2006, pp8-9. www.defra.gov.uk/fish/sea/pdf/turningtide-govresponse.pdf

[10] Jones PJS. The Marine Bill: cornucopia or Pandora's Box? ECOS: A Review of Conservation 2006; 27(2): 1-6. 
Jones P.J.S. (2008) Fishing industry and related perspectives on the issues raised by no-take marine protected area proposals. Marine Policy 32(4), 749-758. doi:10.1016/j.marpol.2007.12.009

[11] Jones PJS. Fishing industry and related views on no-take marine protected area proposals in SW England. Research Report, Department of Geography, University College London. www.homepages.ucl.ac.uk/ ucfwpej/pdf/SWViews.pdf

[12] Gell FR, Roberts CM (2003) Marine reserves for fisheries management and conservation: a winwin strategy. El Anzuelo: European Newsletter on Fisheries and the Environment 11:4-6. www.ieep.org.uk/publications/pdfs/elanzuelo/v11english.pdf

[13] Murray SN, Ambrose RF, Bohnsack JA, Botsford LW, Carr MH, Davis GE, Dayton PK, Gotshall D, Gunderson DR, Hixon MA, Lubchenco J, Mangel M, MacCall A, McArdle DA, Ogden JC, Roughgarden J, Starr RM, Tegner MJ and Yoklavich MM. No-take reserve networks: sustaining fishery populations and marine ecosystems. Fisheries 1999;24(11):11-25.

[14] The science and politics of marine reserves: when planners raise community hopes of higher fishery yields/Scientific opinion on promises of higher fishery yields. MPA News 2005;6(9):1-4.

[15] Pauly D, Christensen V, Guénette S, Pitcher TJ, Sumaila UR, Walters CJ, Watson R and Zeller D. Towards sustainability in world fisheries. Nature 2002;418(6898):689-695.

[16] Roberts CM, Bohnsack JA, Gell F, Hawkins JP and Goodridge R. Effects of marine reserves on adjacent fisheries. Science 2001;294(5548):1920-1923.

[17] Hilborn R, Micheli F and De Leo GA. Integrating marine protected areas with catch regulation. Canadian Journal of Fisheries and Aquatic Science 2006;63:642-649.

[18] Shipp RL (2003) A perspective on marine reserves as a fishery management tool. Fisheries 28(12):10-21.

[19] Sweeting CJ and Polunin NVC. Marine protected areas for management of temperate North Atlantic fisheries: lessons learned in MPA use for sustainable fisheries exploitation and stock recovery. London: DEFRA, 2005. www.defra.gov.uk/marine/pdf/science/mpareportnorthatlantic.pdf

[20] Gell FR and Roberts CM. Benefits beyond boundaries: the fishery effects of marine reserves. Trends in Ecology and Evolution 2003;18(9):448-455.

[21] Hammond PS and Grellier K. Grey seal diet and fish consumption in the North Sea. London: DEFRA, 2005.

[22] Corkeron PJ. Opposing views of the "Ecosystem approach" to fisheries management. Conservation Biology 2006;20(3):617-619.

[23] Yaffee SL. Three faces of ecosystem management. Conservation Biology 1998;13(4):713-725.

[24] Thrush SF, Gray JS, Hewitt JE and Ugland KI. Predicting the effects of habitat homogenization on marine biodiversity. Ecological Applications 2006;16(5):1636-1642.

[25] Tillin HM, Hiddink JG, Jennings S and Kaiser MJ. Chronic bottom trawling alters the functional composition of benthic invertebrate communities on a sea-basin scale. Marine Ecology Progress Series 2006;318:31-45.

[26] Piet GJ and Rijnsdorp AD. Changes in the demersal fish assemblage in the south-eastern North Sea following the establishment of a protected area ("plaice box"). ICES Journal of Marine Science 1998;55:420-429.

[27] Jones PJS. Marine protected area strategies: issues, divergences and the search for middle ground. Reviews in Fish Biology and Fisheries 2001;11(3):197-216.

[28] Ballantine WJ and Langlois TJ. Marine reserves: the need for systems. Paper presented at $41^{\text {st }}$ European Marine Biology Symposium: Challenges to Marine Ecosystems, September 2006, University College Cork, Ireland.

[29] Roberts CM, Hawkins JP and Gell FR. The role of marine reserves in achieving sustainable fisheries. Phil. Trans. R. Soc. B 2005;360:123-132.

[30] Woodhatch L and Crean K. The gentleman's agreement: a fisheries management case from the Southwest of England. Marine Policy 1999; 23(1): 25-35.

[31] Blyth RE, Kaiser MJ, Edwards-Jones G and Hart PJ. Voluntary management in an inshore fishery has conservation benefits. Environmental Conservation 2002;29(4):493-508. 
[32] Blyth RE, Kaiser MJ, Edwards-Jones G and Hart PJ. Implications of a zoned fishery management system for marine benthic communities. Journal of Applied Ecology 2004;49:951-961.

[33] Blyth-Skyrme RE, Kaiser MJ, Hiddink JG, Edwards-Jones G and Hart PJ. Conservation benefits of temperate marine protected areas: variation among fish species. Conservation Biology 2006;20(3):811-820.

[34] Langlois TJ and Ballantine WJ. Marine ecological research in New Zealand: developing predictive models using no-take marine reserves. Conservation Biology 2005;19:1763-1770.

[35] Shears NT and Babcock RC. Continuing trophic cascade effects after 25 years of no-take marine reserve protection. Marine Ecology Progress Series 2003;246:1-16.

[36] Kaiser MJ. Are marine protected areas a red herring or a fisheries panacea? Canadian Journal of Fisheries and Aquatic Science 2005;62(5):1194-1199.

[37] Eastwood PD, Mills CM, Aldridge JN, Houghton CA and Rogers SI. Human activities in UK offshore waters: an assessment of direct physical pressure on the seabed. ICES Journal of Marine Science 2007;64:453-463.

[38] Beddington JR, Agnew DJ and Clark CW. Current problems in the management of marine fisheries. Science 2007;316:1713-

[39] Bohnsack JA. A comparison of short-term impacts of no-take marine reserves and minimum size limits. Bulletin of Marine Science 2000;66(3):635-650.

[40] Gravestock P., independent marine resource management consultant. Personal Communication, European Symposium on Marine Protected Areas, Murcia, Spain, 25-28 September 2007.

[41] Guénette S, Lauck T and Clark C. Marine reserves: from Beverton and Holt to the present. Reviews in Fish Biology and Fisheries 1998;8(3):251-272.

[42] Hilborn R, Stokes K, Maguire J, Smith T, Botsford LW, Mangel M, Orensanz J, Parma A, Rice J, Bell J, Cochrane KL, Garcia S, Hall SJ, Kirkwood GP, Sainsbury K, Stefansson G and Walters C. When can marine reserves improve fisheries management? Ocean \& Coastal Management 2004;47(3/4):197-205.

[43] Davies AJ, Roberts JM and Hall-Spencer J. Preserving deep-sea natural heritage: emerging issues in offshore conservation and management. Biological Conservation 2007;138:299-312.

[44] Erwin DG. Strangford Lough: 40+ years of loss of biodiversity under conservation management. In proceedings: Coastal Futures 2003: review and future trends. Ross-on-Wye, Gloucestershire: Coastal Management for Sustainability, 2003. www.coastms.co.uk 